\title{
Apuntes sobre \\ Arquitectura Colonial
}

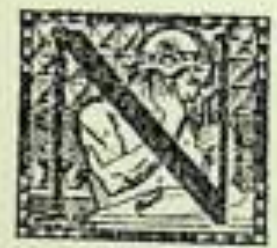

INGUNO de los pueblos modernos se ha erigido en sus colonias un monumento más grandioso que España con sus obras arquitectónicas. En todas partes, alli adonde llegaban españoles. pronto comenzaban sus manos a acarrear piedras y a unirlas para levantar obras de arte.

Hay aún que llenar un gran vacio en la historia del arte humano. ciencia tan cultivada en otros campos de investigaciones: todavia no se ha escrito la historia del arle colonial español. Hasta el día. sólo disponemos de unos pocos estudios imperfectos, escritos sin la preparación y la capacidad necesarias para concebir el espíritu de la época colonial. Pero no hay que extrañarse de este hecho, ya que, hasta ahora, casi la totalidad de nuestros escritores, con muy raras y honrosas excepciones, menospreciaba y hasta delestaba la cultura española. Sólo en los últimos años parece observarse cierta reacción.

Naturalmente. estos breves apuntes adolecen de todos aquellos errores cuya eliminación será la tarea futura de la historia del arie. Sólo pretendemos mostrar algunos de los fenómenos fundamentales de aquel inagotable tesoro que hemos heredado de la España heroica y colonizadora.

Hasta el siglo XVIII, habia en nuestra América dos grandes centros culturales: México y el Perú. Del primero de ellos dependía la América Central. Colombia, Venezucla y el Sur de los actuales Estados, Unidos de Norte América: del segundo, los demás paises sudamericanos. En México. la cullura española se habia desarrollado en una forma mucho más rica y vigorosa que en el Perü: pero también aqui era notable su esplendor.

En el Perú. la arquitectura fué cultivada especialmente por la orden de San Francisco, que tenía por centro cultural la Caledral más hermosa de Sud-América. San Francisco de Lima. Puede observarse la influencia artística de esta orden desde Tumbes, donde desembarcaron los primeros españoles, siguiendo por Lima, Cuzco y La Paz. hasta Tucuman y Córdoba. en Argentina. y en Santiago en Chile. 
En todas aquellas regiones construyeron iglesias y capillas esos arquitectos sin iguales. San Francisco de Lima era el más caracterizado centro cultural de Sud-América. La iglesia forma todo un museo de Bellas Artes. Le estaba agregado un Seminario. en el cual se meditaron, por última vez, los grandiosos sistemas espirituales medioevales, para enconirar pronto su eferno ocaso ante el brillo de las ciencias positivas, que conquistaron el puesto que a ellas correspondia, una vez declarada la independencia de los nuevos estados americanos. La biblioteca de San Francisco contaba, en el siglo XVIII, siete mil volúmcnes: cantidad considerada enorme en aquella época.

El cdificio principal fué construido por el año de 1624. A esta época corresponden las enormes torres. el crucero, la capilla principal y las bóvedas doradas. La nave mide $96 \mathrm{~m}$. de largo y 39 de ancho.

Para analizar el estilo de este edificio, es menester recapilular un poco la historia de la arquitectura, porque el estilo de San Francisco es, al mismo tiempo. una historia de toda la arquilectura colonial.

La fachada perlenece, en lo primordial, al estilo llamado greco-romano, es decir. al renacimiento. No existe en Sud-América ningún edificio que pertenezca al estilo gótico (en México, en cambio, los hay). Es este un hecho muy curioso. ya que los españoles lo aplicaban frecuentemente en aquel tiempo. Si bien el renacimiento habia sido introducido en España en 1480 por el platero Dedro Diez. (de cuyo oficio recibió el nombre). en una variación específicamente española llamada estilo plateresco. sólo rara vez fué empleado en construcciones sagradas. En 1589. (para no mencionar sino un ejemplo), el Capitulo de la Caledral de Salamanca acordó continuar la construcción de la Catedral en el es. tilo gótico puro. En Sud-América, en cambio, aquel estilo no fué empleado jamâs.

En general. los españoles, en sus edificios religiosos, pasaron inmediatamente del estilo gótico al ya nombrado estilo greco-romano, el que da también una nota resaltante a San Francisco.

Fuera de este estilo. puede observarse la influencia de las más variadas tendencias en aquella hermosa catedral.

El portal principal contiene elementos barrocos. Se trata del barroco español, que está caracterizado como simbolo de una pasión vehemente. En la historia del Arte se le denomina estilo churrigueresco. Este barroco español tuvo gran influencia en la arquitectura europea. por haber quitado al barroco francés su severidad, transformándolo en el rococó.

Pero en San Francisco también puede observarse el estilo plateresco. Ya hemos visto más arriba que éste forma en España una elapa entre el estilo gófico y el renacimiento propiamente dicho. Representa una sintesis de aquellos dos estilos y del mudéjar. El estilo plateresco es uno de los más esplendorosos y pintorescos que conoce el arte. En las construcciones profanas ha revelado toda su gala y delicadeza en puertas, ventanas, escudos de armas, patios. etc. Su influencia se extendió también al extranjero. El Portugal lo acogió y transformó en el estilo manuelino. En Flandes, y hasla en el Castillo de Heidelberg. 
puede observarse en ciertos detalles. Siguió al gran Carlos $V$ en sus expediciones a aquellos paises.

Hay en España dos periodos platerescos; el primero reemplazó. como ya hemos demostrado, al estilo gótico; el segundo, al barroco italiano. que también habia encontrado imitadores en España (estilo borrominesco).

Fué, a su vez. reemplazado por el estilo churrigueresco.

Este segundo periodo plateresco influyó también en San Francisco. Las bóvedas del crucero, las paredes revestidas de azulejos, efe., perfenecen a este estilo.

Aquella gigantesca catedral de Lima está caracterizada por su sencillez. 0 . mejor dicho, por su ingenua inocencia. a pesar de los elementos barrocos que contiene. Esta inocencia se asemeja a lo que es en literatura la de Santa Teresa de Jesús, cuya mística encantadora es, en el fondo, contemplativa, si bien a menudo resplandece apasionadamente y que tanta influencia tuvo sobre sus conlemporáneos e imitadores.

San Francisco de Lima es una obra netamente española. Quizás esla observación extrañe a nuestros lectores: pero la verdad es que expresa una excepción. La arquitectura colonial raras veces es española pura. Casi todos los edificios confienen elementos indigenas, que muchas veces llegan a ser predominantes. San Francisco no está del todo libre de ellos; en más de algún ornamento puede observarse la cinceladura de un artifice indio.

La influencia reciproca de las culturas española $\mathrm{e}$ indigena constituye uno de los fenómenos más interesantes de la historia de la colonización. Aun hoy dia hay, en las regiones montañosas boliviano-peruanas. aldeas pobladas casi exclusivamente por indios que han conservado en una forma tan sorprendente las antiguas costumbres españolas. como no se encuentran ni en la misma España. Esla fusión del cristianismo y paganismo fué de tal grado. que aquellos mismos españoles ortodojos y fanáticos empleaban a los indios, poco tiempo después de la conquista, en la construcción y decoración de sus iglesias, y hasta les dejaban tallar las imágenes de sus santos.

Pero no eran sólo los indios los que se apropiaban la cultura española: muy al contrario, sus formas artisticas encontraban también cabida en las iglesias y demás construcciones. Sus manos cubrian las fachadas de ornamentos y decoraciones bizarras, primero timida. más tarde abiertamente. De esta manera, las almas de aquellos dos pueblos tan diferentes se amalgamaron y lusionaron.

En las regiones de la costa. esta influencia indigena es menos poderosa. dominando en el interior. En general. sólo puede observarse en los ornamentos. quedando libres de ella las formas arquitectónicas.

Después de este paréntesis sobre estilos hispano-indios, volvamos a tratar otra vez de nuestra materia.

Fuera de San Francisco, hay en Lima muchas otras obras arquitectonicas de imporlancia. Entre las iglesias. es especialmente digna de mención la de La Merced. Su fachada es uno de los más hermosos ejemplos del arte barrocoindio. Es de una pasión irritante. El signo escalonado indio está muy hábil- 
mente empleado como elemento constructivo, en lugar de los arcos interrumpidos usados comúnmente. Toda la fachada está caracterizada por sus formas vigorosas, viriles. El signo escalonado es de origen mitológico: representa la tierra y el cíclo. y puede observarse en ambas Américas. desde Alaska hasta Tierra del Fuego, formando uno de los elementos más importantes del arte indigena.

Fuera de la fachada. es interesante en La Merced el crucero, de un efecto mistico y agradable. Está construido en el estilo plateresco. con columnas dobles muy armoniosas.

Dejemos los demás edificios sagrados, para decir unas pocas palabras sobre los profanos. Entre éstos ocupan el primer lugar el Palacio de los Marqueses de Torrelagle y el de los señores de Ortiz y Ceballos. Especialmente el primero de ellos reune en si todas las calidades de los diferentes estilos de que hemos hablado. Es una obra de arte llena de donaire y armonia. Digna de mención. es, sobre todo, una de sus fachadas, por la metamorfosis que sufrió en ella el signo escalonado. En este palacio puede estudiarse. como en un cjemplo clásico. la fusión de las culturas española e indigena.

El patio del Palacio Ortiz y Ceballos no es menos hermoso que el edificio a que nos acabamos de referir.

Si nos alejamos de Lima para penetrar en el interior del Continente, a menudo salta a la vista la gran semejanza que existe entre aquellos paisajes y los de Andalucia. El arte español subraya esta semejanza. Casi todas las obras coloniales han experimentado la influencia de Andalucia. Muchas veces es dificil definir a la primera vista si se trata de una obra andaluza o sud-americana.

Aquella influencia andaluza da a los edificios cierta sencillez encantadora que rara vez se encuentra en otras partes. Se debe a ella, además, la policromía que los caracteriza. El Beaterio de las Carmelitas Descalzas de Arequipa tiene, por cjemplo, una nave de color azul de una delicadeza extraordinaria.

Pero también en Arequipa la influencia indigena es grande. La fachada de La Compañia está cubierta de un sinnúmero de ornamentos que representan signos mitológicos cristianos. árabes e indios. De la misma manera. numerosas obras profanas revelan la importancia de la corriente artistica indigena.

La Caledral de Cuzco tiene mucha semejanza con aquellas antiguas iglesias españolas. construidas en forma de fortificaciones. tan frecuentes en la Edad Media (ejemplo: la Catedral de Avila). También en Cuzco el barroco es más viril, sereno y majestuoso que en Europa. si bien guarda el carácter apasionado y vibrante que caracteriza a aquel estilo. Quizás esta serenidad sea debida a la influencia indigena.

El crucero de Santo Domingo está construido en el estilo mudéjar andaluz. Otro edificio admirable. Ileno de vigor y altivez, es la Universidad.

Los españoles no construian obras monumentales solamente en las grandes ciudades. Aldeas solitarias y casi despobladas tienen a menudo soberbias iglesias: por ejemplo. Juliaca. En Puno se encuentra un arco triunfal. Hermosas obras arquitectónicas se encuentran también en Oruro y Cochabamba. 
En Potosi es especialmente digna de mención la puerta principal de San Lorenzo. Quizás es ésta la obra más hermosa que existe en Sud-América, entre las que pertenecen al arte hispano-indio. Las grandes lineas arquitectónicas son barrocas: pero casi todos los detalles son indigenas. La estatua de San Lorenzo es una figura pequeña y parece un idolo indio. Todas las demás estatuas han sido talladas por artifices indigenas y son de un carácter casi nefamente indio. Como ornamentos, se han empleado el sol, la luna, animales y plantas. Casi todos pueden encontrarse en el arte prehispánico: pero han experimentado en San Lorenzo la influencia del cristianismo y semejan. en ciertos detalles, ornamentos cristiano-ắrabes.

Una de las ciudades más interesantes de Sud-América, respecto a sus obras arquitectónicas, es $\mathrm{La}$ Paz. Más que en cualquiera otra parte predomina en ella la influencia andaluza.

Pasemos de Bolivia a la Argentina. La arquitectura colonial está aquí muy bien representada en Córdoba y ha experimentado la influencia de dos corrienles extranjeras: una de ellas parle de Lima y sigue por Jujuy. Salta. Tucumán y Córdoba, para terminar en Buenos Aires. Es sabido que Argentina dependia politica y hasta comercialmente del Perú durante casi toda la Colonia. Sólo en 1778 fué establecido el virreinato de Buenos Aires.

La segunda corriente cruza a la primera verticalmente y tiene su punto de salida en las Misiones de los Jesuitas, en el Daraná.

Esta Orden avanzó desde alli hacia el suroeste, estableciendo misiones por todas partes. Más de una iglesia se encuentra aun hoy dia en algún risco solilario de la región andina, en el norte del territorio argentino. Todas ellas están caracterizadas por ese estilo tan apasionado y fanático. que se ha llegado a llamar estilo jesuifa.

Ambas corrientes, la de Lima y la de Misiones, se cruzaron en varios puntos, formando un nuevo y original estilo.

La influencia indigena es poco importante en la arquitectura argentina. En estas regiones, el indio se encontraba en un estado de cultura muy inferior al del Perú. Su capacidad creadora en el arte estaba poco desarrollada en los tiempos de la conquista. Sólo unas pocas lineas nerviosas en algunas construcciones parecen demostrar cierta influencia india, como también ciertas arcadas de formas extrañas que se empleaban en los portales de algunos edificios (p. ej.. en la iglesia de Candonga. cerca de Córdoba).

La inmensa y desoladora monotonía de la Pampa argentina ha quitado al barroco toda su pasión y excitación efervescente. Frente de aquellos llanos infinitos. parece caer de los edificios todo ornamento y quedar sólo las grandes masas y lineas.

Asi. puede considerarse el Cabildo de Lujän como una encarnación de la Pampa, que es difícil imaginarse más grandiosa. De lodas maneras, esta obra demuestra la alta cultura arlistica de los españoles. Como en todas partes, ajustaron también aqui el carácter de sus edificios al ambiente. de manera que sus 
obras artisticas forman una creación espiritual acomodada al carácier del poisaje que las rodea.

En Chile. casi todos los testimonios de la arquitectura colonial se encuentran reunidos en Santiago, con raras excepciones. Nuestro pais era el más pobre de todos los que pertenecian a la corona española. Sólo unas cuantas migajas del hermoso tesoro arquitectónico de España llegaron a caer en estesuelo guerrero.

La Casa Colorada de don Mateo de Toro Zambrano constituye una joya preciosa. Construida en el siglo XVIII. perlenece fodavia en cuanto a su estilo a la antigua escuela de Lima, que en aquella época dominaba aún en nuestro continente. El rococó jamás encontró camino allende el gran océano.

El mundo español se encontraba en un estado de agonia: había consumido todas las posibilidades que el destino tenia reservados a su entidad histórica.

Entre las obras religiosas. es digno de mención el templo de Santo Domingo, y especialmente sus altares barrocos. San Francisco posee una hermosa puerta de estilo plateresco (sacristia). En ella pueden estudiarse todos los primores. toda la delicadeza de este estilo.

Paseando por las calles de nuestra capital. se encontrará más de una mansiôn colonial con su gran portón. su balcón y sus decoraciones antiguas. Están caracterizadas por la sencillez del material y de la construcción, prueba clocuenle de la pobreza de esta colonia.

En marcado contraste con ella se encuentra el único edificio monumental que poseemos del tiempo colonial, la Moneda. Su arquitecto. Toesca. continuó la tradición de la gran escuela de Lima; pero, a pesar de ello, pueden observarse en este edificio algunas influencias posteriores europeas: ciertas lineas pertenecen al clasicismo. o sea. a la última gran escuela arquitectónica que produjo la vieja Europa. No cabe la menor duda que la Moneda. construida por los españoles en los últimos años de la Colonia. es aun hoy dia la obra arquitecfónica más importante que poseemos en Chile.

Nuestro actual palacio presidencial ha servido de modelo a otro edificio de bastante mérito: nos referimos a aquél en que se encuentra actualmente la $D i$ rección General de Correos (antiguo Dalacio de los Tribunales).

Cerca de Valdivia. existen. en la desembocadura del rio del mismo nombre. algunas ruinas antiguas que pertenecen a la gran escuela de Lima.

Hecho un rápido bosquejo arquitectónico del eúltimo rincón del mundo. terminaremos estos breves apuntes sobre arquitectura colonial. Dero no lo haremos sin agregar algunas consideraciones generales.

Nuestro ensayo nos parece probar en forma fehaciente que los espoñoles no eran aquellos bárbaros que nos pintan a menudo los historiadores. La época colonial es. desde muchos puntos de vista, una de las más interesantes de la historia universal. Si las colonias españolas no progresaron de la misma mane- 
ra que las inglesas y holandesas, no fué por mala intención de los conquistadores y colonizadores: España dió a América su sangre más castiza. La decadencia de las colonias americanas se explica por el agotamiento fisiológico de la raza española que comenzó en el siglo XVII. es decir. en el preciso momento en que daba comienzo el desarrollo capitalista moderno. España abarcaba en aquella época países tan vastos y extendidos, que su sangre no bastaba para dar vida a todos ellos. La peninsula se despobló: sus numerosos enemigos la hacian una guerra incesante, perdiendo el pais en ella sus mejores fuerzas: y asi. aquel imperio en el cual el sol no se ponia tuvo que agotarse. La idea de una monarquía mundial era muy grande. muy elevada para los débiles hombros de seres humanos.

Goethe dijo en alguna ocasión que es necesario proceder de vez en cuando a una revisión de nuestros conceplos históricos: nos parece que ha llegado la hora de corregir nuestros conceplos sobre la España colonial.

CARLOS KELLER R.

Concepción, 1924. 